Annals of Plant Sciences

\title{
Phytotoxic potential of essential oil of Melaleuca leucadendra against some agricultural weeds
}

Gunjan Goyal

Department of Botany, Panjab University, Chandigarh, India.

Received: 10/16/2017; Accepted: 10/30/2017

\begin{abstract}
The work was undertaken to investigate the phytotoxic potential of essential oil from Melaleuca leucadendra against three weed species, viz., Echinochloa crus-galli, Cyperus rotundus and Leptocbloa chinensis. It was observed that volatile oil (0.25-1.5 mg ml-1) of Melaleuca retarded the germination and growth of all the test weeds in a dose-response bioassay conducted under laboratory conditions. Generally, both root and shoot length showed an inhibitory effect in a concentration dependent manner and the maximum effect was observed in C. rotundus, followed by E. crus-galli and $L$. cbinensis. The Melaleuca oil not only affected the germination and seedling growth of the test weeds, but also inhibited the chlorophyll content and dry weight. At the highest dose of Melaleuca oil treatment $\left(1.5 \mathrm{mg} \mathrm{ml}^{-1}\right)$, the chlorophyll content declined by nearly $50 \%$ in E. crus-galli and $90 \%$ in L. cbinensis over the control. Thus, it is concluded that volatile oil possesses phytotoxic potential towards other plants and could be further explored for weed management.
\end{abstract}

Keywords: Phytotoxicity, Weed management, Melaleuca leucadendra, Growth inhibition

\section{Introduction}

A large number of aromatic plants possessing naturally occurring substances have been in use since ancient times. Essential oils form one such class of natural products which find utility in various products such as in foods, cosmetics, medicines, as antimicrobial/ insecticidal agents, insect repellants (Dorman and Deans, 2000; Isman and Machial, 2006; Bakkali et al., 2008). These functional elements are earning importance these days because of the negative health effect associated with the use of synthetic products. Nowadays, scientists have shown considerable interest in the phytotoxic potential of different essential oils. The essential oils extracted from aromatic plants are becoming popular with the potential to control weeds because of their structural and chemical diversity (Singh et al., 2003; Bakkali et al., 2008; Duke and Dayan, 2015). Due to the important benefits of essential oil including biodegradable nature (Zygadlo and Grosso, 1995), ecofriendly behavior, minimum mammalian toxicity (Dayan et al., 2012), short environmental half-lives, tendency to affect novel target sites (Grana et al., 2013) and impersistent in soil and water (Isman, 2006), they have the potential to be used as bio-herbicides (Batish et al., 2008; Pinheiro et al., 2015; Grichi et al., 2016). In view of phytotoxicity and weed suppressing ability of volatile essential oils and their constituents against weeds, it is thus pertinent to study the aromatic plant to scrutinize its phytotoxic ability with an aim of using them for weed management.

Melaleuca leucadendra, commonly called as Cajuput tree, is native to Australia and Southeast Asia. It is

\footnotetext{
${ }^{*}$ Corresponding Author:

Gunjan Goyal,

Department of Botany,

Panjab University, Chandigarh, India.

E-mail: gunjangoyal14@gmail.com
}

moderately fast growing perennial evergreen tree, and mainly occurs near river flats, coastal plains or seasonal swamps (Anonymous, 2003). It is cultivated in parks and gardens as an ornamental tree. It has bright green foliage, straight and long flexible trunk with pendulous branching and spongy lamellate bark. The inflorescence is terminal and dense flowers occur in triads. The plant is used for various purposes such as timber, mulch and its essential oil as a source of medicine (Bodle, 1998). Volatile oil of tea tree plant is used to cure the acne problem (Bassett et al., 1990), dandruff (Satchell et al., 2002) and oral candidiasis (Vazquez and Zawawi, 2002). It also possesses a number of biological activities including antitermite (Sakasegawa et al., 2003), antiviral (Cleber et al., 2007) and antifungal activities (Lee et al., 2008). Pujiarti et al. (2012) reported bioactive potential of the leaf oil components exhibiting antioxidant, antihyaluronidase and antifungal activities. However, the information regarding the phytotoxicity of $M$. leucadendra oil towards weeds is largely lacking. Therefore, the present study was planned to assess the phytotoxicity of volatile essential oil from $M$. leucadendra.

\section{Materials and Methods}

Plant material: Melaleuca leucadendra is a perennial plant, found in parks and gardens in India. Leaves of the plant were collected from the Botanical Garden of Panjab University campus, Chandigarh, India.

Essential oil extraction: The essential oil was extracted from the plant material (leaves) by steam 
distillation process using Clevenger's apparatus. Nearly two kg of freshly collected plant material was mixed with $1 \mathrm{~L}$ of water. The mixture was boiled for $3 \mathrm{~h}$ and the oil was collected from the nozzle of the condenser. The obtained essential oil was dried over anhydrous sodium sulphate and stored at $4^{\circ} \mathrm{C}$ until tested.

Collection of seeds: Seeds of the weeds, Echinochloa crus-galli (L.) Beauv., Cyperus rotundus L., and Leptochloa chinensis (L.) Nees were collected from the wild stands growing abundantly in and around Panjab University campus, Chandigarh. The test weeds were selected as they are economically important, troublesome and commonly found in agriculture fields.

Growth bioassay: Viable and healthy seeds of the test weeds were scarified individually with $2 \%$ sodium hypochlorite for 2 min followed by rinsing with distilled water and finally imbibed in distilled water for $24 \mathrm{~h}$. For their treatment in solution form, various concentrations $(0.25-1.5 \mathrm{mg} / \mathrm{ml})$ were prepared by dissolving oil in water with the help of Tween-20. Petri dishes of $15 \mathrm{~cm}$ were lined with two layers of Whatman No. 1 filter circle and was moistened with $10 \mathrm{ml}$ of different oil concentrations (Batish et al., 2004). After 7 days of treatment, growth of test weeds was measured in terms of percent germination and seedling growth (root length and shoot length) under laboratory conditions. Leaves of test plants were taken for chlorophyll content estimation.

Estimation of total chlorophyll content: The total chlorophyll content from the leaves of the test species was extracted in dimethyl sulphoxide (DMSO) following the method of Hiscox and Israelstam (1979). The extinction value of chlorophyll extracted in DMSO was measured at a dual wavelength of 645 and $663 \mathrm{~nm}$ on Shimadzu UV- 1800 double beam spectrophotometer, using DMSO as blank. The amount of chlorophyll was calculated using the Arnon's equation (1949). It was expressed in $\mu \mathrm{g} \mathrm{mg}^{-1}$ dry weight (DW) of the tissue as suggested by Rani and Kohli (1991).

Statistical analysis: The statistical analysis of data was done using one-way analysis of variance followed by separation of treatment means from the control by using post hoc Tukey's test at $P \leq 0.05$ significance level using software program SPSS (Version 16.0).

\section{Results and Discussion}

The germination of all the test weeds was significantly reduced in a concentration-dependent manner. At lower concentration $\left(0.25 \mathrm{mg} \mathrm{ml}^{-1}\right)$ of oil, minimum inhibition in germination of the weeds $(14.24 \%$ in E. crus-galli, $51.67 \%$ in C. rotundus and $33.33 \%$ in L. chinensis) over the control was noticed (Fig. 1). The reduction was greater with increasing amount of Melaleuca oil. At highest concentration $\left(1.5 \mathrm{mg} \mathrm{ml}^{-1}\right)$, maximum inhibition was noticed in C. rotundus $(100 \%)$ followed by $L$. chinensis $(79.63 \%)$, and E. crus-galli $(70.87 \%)$ over the control (Fig. 1). The observations made in the present study are parallel to earlier studies documenting the inhibition of seed germination in response to essential oils (Singh et al., 2009; Grichi et al., 2016; Ricci et al., 2017). From the previous studies, it has been known that the essential oil exhibited potent inhibitory effect on germination and growth, and causing morphological and physiological changes in the plant seedlings (Kordali et al., 2015; Bali et al., 2016). The mechanism of the inhibitory action of essential oils remains unclear, although it has been reported that essential oil, mainly their constituent's monoterpenes, inhibit the cell division of apical meristems (Nishida et al., 2005; Singh et al., 2009).

Fig.1: Effect of $M$. leucadendra oil on germination $(\%)$ of test weeds measured after 7 days of exposure.

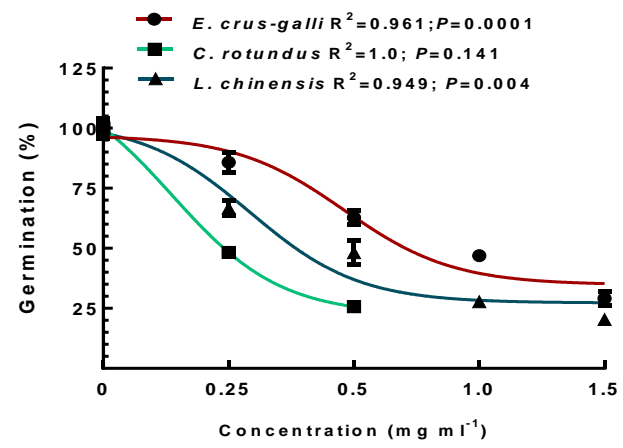

Data represented as mean \pm SE and analysed by linear regression; $\mathrm{R}^{2}$ represents coefficient of determination; Data is significant for all weeds at $P \leq 0.05$ except for $C$. rotundus

Fig.2: Effect of $M$. leucadendra oil on root length (cm) of test weeds measured after 7 days of exposure.

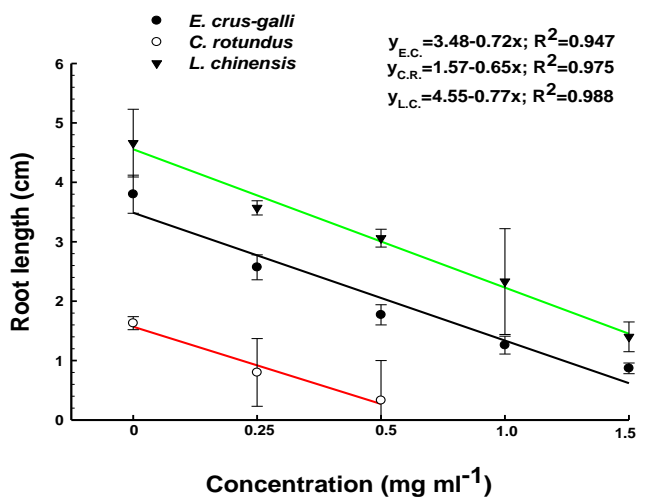

Data represented as mean \pm S.E. Data analysed by linear regression; $\mathrm{R}^{2}$ represents coefficient of determination; Data is significant for all the weeds at $P \leq 0.05$ except for $C$. rotundus. 
Fig. 3: Effect of $M$. leucadendra oil on shoot length $(\mathrm{cm})$ of test weeds measured after 7 days of exposure.

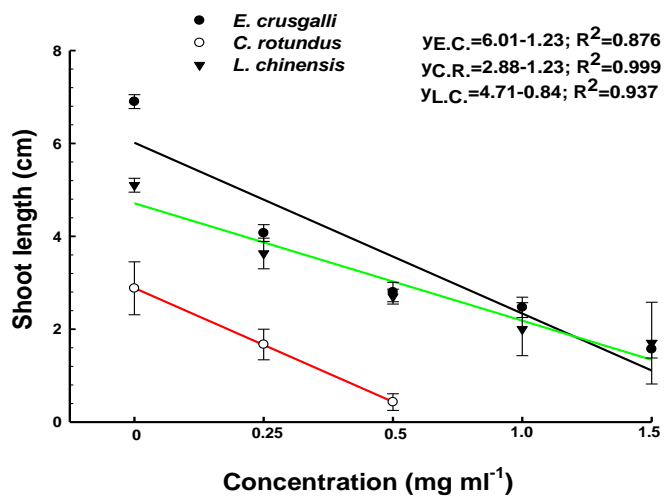

Data represented as mean \pm S.E. Data analysed by linear regression; $\mathrm{R}^{2}$ represents coefficient of determination; Data is significant for all the weeds at $P \leq 0.05$.

Fig. 4: Effect of $M$. leucadendra oil on dry weight (mg) of test weeds measured after 7 days of exposure.

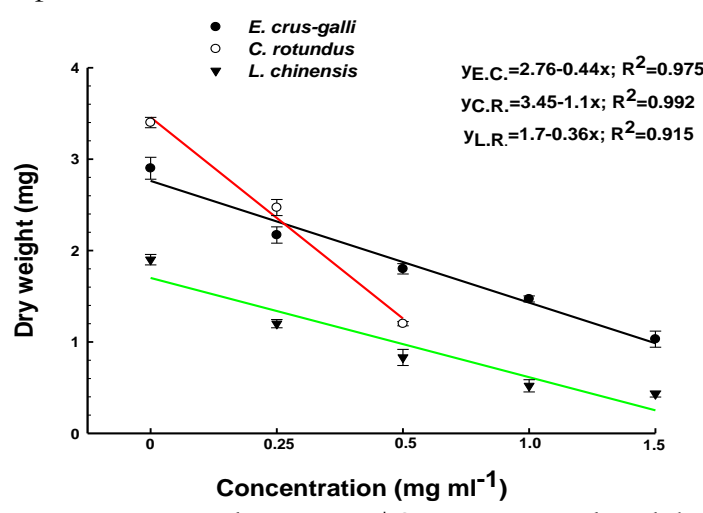

Data represented as mean \pm S.E. Data analysed by linear regression; $\mathrm{R}^{2}$ represents coefficient of determination; Data is significant for all the weeds at $P \leq 0.05$.

Fig. 5: Effect of $M$. leucadendra oil on total chlorophyll content ( $\mu \mathrm{g} \mathrm{mg}^{-1} \mathrm{DW}$ ) of test weeds measured after 7 days of exposure.

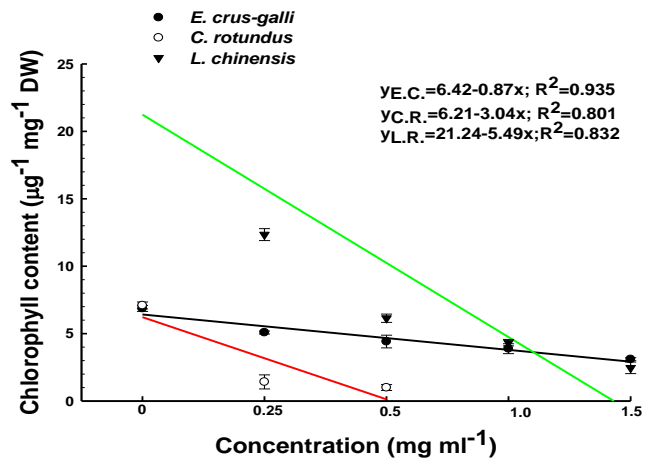

Data represented as mean \pm S.E. Data analysed by linear regression; $\mathrm{R}^{2}$ represents coefficient of determination; Data is significant for all the weeds at $P \leq 0.05$ except for $C$. rotundus.
Further, seedling growth measured in terms of root and shoot length in the test weeds declined in a dose dependent manner in response to Melaleuca oil treatment. A significant reduction in the root length ranging from $\sim 33$ to $77 \%$ in E. crus-galli, 23 to $70 \%$ in L. chinensis and 51 to $100 \%$ in C. rotundus over the control was observed in response to $0.25-1.5 \mathrm{mg} \mathrm{ml}^{-}$ ${ }^{1}$ of Melaleuca oil (Fig. 2). The reduction was greater with an increase in the amount of Melaleuca oil. Likewise, the shoot length of test weeds was significantly reduced in response to Melaleuca oil. It was reduced by nearly $41 \%, 59 \%, 64 \%$ and $77 \%$ at $0.25,0.5,1.0,1.5 \mathrm{mg} \mathrm{ml}^{-1}$ respectively over that of control in E. crus-galli (Fig. 3). The shoot length in C. rotundus also declined significantly upon exposure to different concentration of oil. It decreased by nearly $42 \%, 89 \%$ and $100 \%$ at $0.25,0.5,1.0 \mathrm{mg} \mathrm{ml}^{-1}$, respectively, over the control (Fig. 3). In case of $L$. chinensis, shoot length declined significantly by $29 \%$, $47 \%, 61 \%$ and $66 \%$ at $0.25,0.5,1.0,1.5 \mathrm{mg} \mathrm{ml}^{-1}$ of the oil over that in the control (Fig. 3). The growth retardatory effects of Melaleuca oil on the test plants is in agreement with earlier studies reporting inhibitory effect of volatile oils from aromatic plants on the seedling growth of weeds (Singh et al., 2009; Rolli et al., 2014, Arora et al., 2016; Ricci et al., 2017). The reduction in early growth of weeds could be due to the inhibitory effect of plant volatiles on the cell division and lowered root mitotic activity, DNA synthesis of growing root tips and disruption of the membranes (Nishida et al., 2005; Ahuja et al., 2015). The effect might be attributed either to high percent of main constituent or to synergy among different oil constituents.

The dry weight of all the test weed seedlings decreased significantly in response to Melaleuca oil treatment. The percent reduction in dry weight varied from species to species. The dry weight of $E$. crus-galli, C. rotundus and L. chinensis declined by $25-64 \%, 27-100 \%$ and $37-77 \%$ respectively, in response to Melaleuca oil $\left(0.25-1.5 \mathrm{mg} \mathrm{ml}^{-1}\right)$ over the control (Fig. 4). A loss in weight of the plants could be possibly due to the accumulation of less carbon in the plant (Batish et al., 2007).

Further, chlorophyll content declined upon exposure to different concentrations of Melaleuca oil. The decline in total chlorophyll content was observed in all the test weeds in a dose-dependent manner. At highest concentration of $1.5 \mathrm{mg} \mathrm{ml}^{-1}$ of Melaleuca oil, the chlorophyll content declined by $55 \%$ in E. crus-galli and $90 \%$ in L. chinensis over the control (Fig. 5). Among the weeds, C. rotundus was the most affected followed by $L$. chinensis and $E$. crus-galli. The observation made in the present study is in parallel to previous reports where volatile allelochemicals were found to decrease the chlorophyll content in the plants and consequently interferes with the photosynthetic activity of the plants (Batish et al., 2004; Kaur et al., 2010; Araniti et al., 2017). Although the exact cause of decrease in 
the total chlorophyll content is not known, it could be either due to inhibition of chlorophyll synthesis or enhanced chlorophyll degradation or both (Yang et al., 2004; Chowhan et al., 2013).

\section{Conclusion}

From the present study, it could be concluded that Melaleuca oil exhibits phytotoxic activity towards all the test weeds by suppressing the germination and early seedling growth of the test plants. Therefore, it holds good potential to be useful for developing natural herbicides.

\section{Acknowledgement}

Gunjan Goyal is thankful to University Grant Commission, India for providing financial assistance for research facilities.

\section{References}

1. Ahuja, Nitina, Harminder Pal Singh, Daizy Rani Batish, and Ravinder Kumar Kohli. "Eugenolinhibited root growth in Avena fatua involves ROSmediated oxidative damage." Pesticide biochemistry and physiology 118 (2015): 64-70. Print.

2. Anonymous, Melaleuca Linn. In the Wealth of IndiaRaw Materials, Vol. VI: L-M, pp. 319-320. National Institute of Science Communication and Information Resources, Council of Scientific and Industrial Research, New Delhi, India, 2003. Print.

3. Araniti, F., A. M. Sánchez-Moreiras, E. Graña, M. J. Reigosa, and M. R. Abenavoli. "Terpenoid trans-caryophyllene inhibits weed germination and induces plant water status alteration and oxidative damage in adult Arabidopsis." Plant Biology 19.1 (2017): 79-89. Print.

4. Arnon, Daniel I. "Copper enzymes in isolated chloroplasts. Polyphenoloxidase in Beta vulgaris." Plant physiology 24.1 (1949): 1. Print.

5. Arora, Komal, Daizy Batish, Harminder Pal Singh, and Ravinder Kumar Kohli. "Comparative account of allelopathic potential of essential oil of Tagetes minuta L. and its major component cis- $\beta$ Ocimene." Annals of Plant Sciences 5.09 (2016): 14281431. Print.

6. Bakkali, Fadil, Simone Averbeck, Dietrich Averbeck, and Mouhamed Idaomar. "Biological effects of essential oils-a review." Food and chemical toxicology 46.2 (2008): 446-475. Print.

7. Bali, Aditi Shreeya, Daizy R. Batish, and Harminder Pal Singh. "Phytotoxicity of Callistemon viminalis essential oil against some weeds." Annals of Plant Sciences 5.10 (2016): 1442-1445. Print.

8. Bassett, I. B., D. L. Pannowitz, and R. S. Barnetson. "A comparative study of tea-tree oil versus benzoylperoxide in the treatment of acne." The Medical Journal of Australia 153.8 (1990): 455-458. Print.
9. Batish, Daizy Rani, Nidhi Setia, Harminder Pal Singh, and Ravinder Kumar Kohli. "Phytotoxicity of lemon-scented eucalypt oil and its potential use as a bioherbicide." Crop Protection 23.12 (2004): 12091214. Print.

10. Batish, Daizy Rani, Harminder Pal Singh, Ravinder Kumar Kohli, and Shalinder Kaur. "Eucalyptus essential oil as a natural pesticide." Forest Ecology and Management 256.12 (2008): 2166-2174. Print.

11. Batish, Daizy Rani, Harminder Pal Singh, Nidhi Setia, Ravinder Kumar Kohli, Shalinder Kaur, and Surender Singh Yadav. "Alternative control of littleseed canary grass using eucalypt oil." Agronomy for sustainable development 27.3 (2007): 171-177. Print.

12. Bodle, M. "Dial M for melaleuca." Wildland Weeds 1.2 (1998): 9-10. Print.

13. Chowhan, Nadia, Harminder Pal Singh, Daizy R. Batish, Shalinder Kaur, Nitina Ahuja, and Ravinder K. Kohli. " $\beta$-Pinene inhibited germination and early growth involves membrane peroxidation." Protoplasma 250.3 (2013): 691-700. Print.

14. Silva, Cleber J., Luiz CA Barbosa, Célia RA Maltha, Antônio L. Pinheiro, and Fyaz Ismail. "Comparative study of the essential oils of seven Melaleuca (Myrtaceae) species grown in Brazil." Flavour and fragrance journal 22.6 (2007): 474-478. Print.

15. Dayan, Franck E., Daniel K. Owens, and Stephen O. Duke. "Rationale for a natural products approach to herbicide discovery." Pest management science 68.4 (2012): 519-528. Print.

16. Dorman, H. J. D., and S. G. Deans. "Antimicrobial agents from plants: antibacterial activity of plant volatile oils." Journal of applied microbiology 88.2 (2000): 308-316. Print.

17. Duke, Stephen O., and Franck E. Dayan. "Discovery of new herbicide modes of action with natural phytotoxins." In Discovery and Synthesis of Crop Protection Products, pp. 79-92. American Chemical Society, 2015. Print.

18. Graña, E., T. Sotelo, C. Díaz-Tielas, F. Araniti, U. Krasuska, R. Bogatek, M. J. Reigosa, and A. M. Sánchez-Moreiras. "Citral induces auxin and ethylene-mediated malformations and arrests cell division in Arabidopsis thaliana roots." Journal of Chemical Ecology 39.2 (2013): 271-282. Print.

19. Grichi, Aida, Zouhair Nasr, and Mohamed Larbi Khouja. "Phytotoxic Effects of Essential Oil from Eucalyptus lehmanii against Weeds and its Possible Use as a Bioherbicide." Bulletin of Environment, Pharmacology and Life Sciences 5 (2016): 17-23. Print.

20. Hiscox, JD T., and G. F. Israelstam. "A method for the extraction of chlorophyll from leaf tissue without maceration." Canadian journal of botany 57.12 (1979): 1332-1334. Print.

21. Isman, Murray B. "Botanical insecticides, deterrents, and repellents in modern agriculture and an 
increasingly regulated world." Annual Review of Entomology 51 (2006): 45-66. Print.

22. Isman, Murray B., and Cristina M. Machial. "Pesticides based on plant essential oils: from traditional practice to commercialization." Advances in phytomedicine 3 (2006): 29-44. Print.

23. Kaur, Shalinder, Harminder Pal Singh, Sunil Mittal, Daizy Rani Batish, and Ravinder Kumar Kohli. "Phytotoxic effects of volatile oil from Artemisia scoparia against weeds and its possible use as a bioherbicide." Industrial Crops and Products 32.1 (2010): 54-61. Print.

24. Kordali, Saban, Aysema Tazegul, and Ahmet Cakir. "Phytotoxic effects of Nepeta meyeri Benth. extracts and essential oil on seed germinations and seedling growths of four weed species." Records of Natural Products 9.3 (2015): 404. Print.

25. Lee, Yeon-Suk, Junheon Kim, Sang-Chul Shin, Sang-Gil Lee, and Il-Kwon Park. "Antifungal activity of Myrtaceae essential oils and their components against three phytopathogenic fungi." Flavour and Fragrance Journal 23.1 (2008): 2328. Print.

26. Nishida, Nami, Satoshi Tamotsu, Noriko Nagata, Chieko Saito, and Atsushi Sakai. "Allelopathic effects of volatile monoterpenoids produced by Salvia leucophylla: inhibition of cell proliferation and DNA synthesis in the root apical meristem of Brassica campestris seedlings." Journal of chemical ecology 31.5 (2005): 1187-1203. Print.

27. Pinheiro, Patrícia Fontes, Adilson Vidal Costa, Thammyres de Assis Alves, Iasmini Nicoli Galter, Carlos Alexandre Pinheiro, Alexandre Fontes Pereira, Carlos Magno Ramos Oliveira, and Milene Miranda Praça Fontes. "Phytotoxicity and cytotoxicity of essential oil from leaves of Plectranthus amboinicus, carvacrol, and thymol in plant bioassays." Journal of agricultural and food chemistry 63.41 (2015): 8981-8990. Print.

28. Rini, Pujiarti, Yoshito Ohtani, and Hideaki Ichiura. "Antioxidant, anti-hyaluronidase and antifungal activities of Melaleuca leucadendron Linn. leaf oils." Journal of wood science 58.5 (2012): 429-436. Print.

29. Daizy, R. A. N. I., and R. K. Kohli. "Fresh matter is not an appropriate relation unit for chlorophyll content: experiences from experiments on effect of herbicide and allelopathic substance." Photosynthetica 25.4 (1991): 655-657. Print.

30. Ricci, Donata, Francesco Epifano, and Daniele Fraternale. "The Essential Oil of Monarda didyma
L.(Lamiaceae) Exerts Phytotoxic Activity in Vitro against Various Weed Seed." Molecules 22.2 (2017): 222. Print.

31. Rolli, Enrico, Matteo Marieschi, Silvia Maietti, Gianni Sacchetti, and Renato Bruni. "Comparative phytotoxicity of 25 essential oils on pre-and postemergence development of Solanum lycopersicum L.: A multivariate approach." Industrial Crops and Products 60 (2014): 280-290. Print.

32. Sakasegawa, Miyusse, Keko Hori, and Mitsuyoshi Yatagai. "Composition and antitermite activities of essential oils from Melaleuca species." Journal of Wood Science 49.2 (2003): 181-187. Print.

33. Satchell, Andrew C., Anne Saurajen, Craig Bell, and Ross StC Barnetson. "Treatment of dandruff with $5 \%$ tea tree oil shampoo." Journal of the American Academy of Dermatology 47.6 (2002): 852-855. Print.

34. Singh, H. P., Daizy R. Batish, and R. K. Kohli. "Allelopathic interactions and allelochemicals: new possibilities for sustainable weed management." Critical reviews in plant sciences 22.3-4 (2003): 239-311. Print.

35. Singh, Harminder Pal, Shalinder Kaur, Sunil Mittal, Daizy Rani Batish, and Ravinder Kumar Kohli. "Essential oil of Artemisia scoparia inhibits plant growth by generating reactive oxygen species and causing oxidative damage." Journal of chemical ecology 35.2 (2009): 154-162. Print.

36. Vazquez, Jose A., and Ahmad A. Zawawi. "Efficacy of alcohol-based and alcohol-free melaleuca oral solution for the treatment of fluconazole-refractory oropharyngeal candidiasis in patients with AIDS." HIV clinical trials 3.5 (2002): 379-385. Print.

37. Yang, Chi-Ming, Feng Chang, Shu-Jin Lin, and Chang-Hung Chou. "Effects of three allelopathic phenolics on chlorophyll accumulation of rice (Oryza sativa) seedlings: II. Stimulation of consumption-orientation." Botanical Bulletin of Academia Sinica45 (2004). Print.

38. Zygadlo, J. A., and N. R. Grow. "Comparative study of the antifungal activity of essential oils from aromatic plants growing wild in the central region of Argentina." Flavour and fragrance journal 10.2 (1995): 113-118. Print.

\section{Cite this article as:}

Gunjan Goyal. Phytotoxic potential of essential oil of Melaleuca leucadendra against some agricultural weeds. Annals of Plant Sciences 6.11 (2017) pp. 1799-1803.

doi: http://dx.doi.org/10.21746/aps.2017.6.11.14

Source of support: University Grant Commission, New Delhi, India.

Conflict of interest: None Declared 